\title{
Monogenic diabetes - an unappreciated problem among physicians
}

\author{
Elżbieta Niechciał, Bogda Skowrońska, Anna Gertig-Kolasa, Izabela Krzyśko, Piotr Fichna
}

Department of Pediatric Diabetes and Obesity, Poznan University of Medical Sciences, Poland

\begin{abstract}
Monogenic diabetes results from one or more mutations in a single gene. It is a relatively rare genetic condition, therefore, it was frequently unappreciated among clinicians. Consequently, monogenic diabetes is misdiagnosed as type 1 diabetes or type 2 diabetes. Such misclassification leads to an inappropriate treatment, often inconvenient for the patients, such as insulin injections with their permanent glycemic control. The correct diagnosis may completely change previous methods of treatment. Patients diagnosed with GCK mutations may be completely treated with adequate diet. HNF1A/HNF4A affected patients are extremely sensitive to low dose sulphonylureas. Moreover, the exact diagnosis has an impact on patients' relatives. Mostly, misdiagnosing of monogenic diabetes is caused by its rare occurrence and insufficient training in this area among physicians. According to different studies it may comprise $1-4 \%$ of all cases of diabetes. The aim of this article is to emphasize that despite the fact that monogenic diabetes is an uncommon disease, it should always be considered in cases of diabetes with unusual course.
\end{abstract}

Key words: monogenic diabetes, prevalence, diagnosis, treatment.

\section{Introduction}

Proper function of insulin-producing pancreatic betacells is crucial for the regulation of glucose homeostasis. Pancreatic beta-cells secrete insulin in amounts appropriate to the respective blood glucose concentration. In brief, glucose is taken up by the beta-cells via glucose transporter 2 . It is then phosphorylated to glucose-6-phosphate by an islet specific glucokinase, resulting in an increase in adenosine triphosphate (ATP) concentration [1]. Rising ATP levels close ATP-sensitive potassium channel (KATP channel, intramembrane cellular channel controlling $\mathrm{K}^{+}$efflux depending on ATP concentration) and lead to cell membrane depolarization. The beta-cell KATP channel is a complex of 2 subunits: Kir6. 2 (inwardly rectifying potassium-channel subunit) and SUR1 (regulatory sulfonylurea-receptor subunit) and both are needed for the correct function of the channel [2].
Thereby beta cells react with opening calcium channel, enabling $\mathrm{Ca}++$ influx and together with calmodulin allowing the release of secretory granules containing previously synthesized insulin. In addition, other factors such as hepatocyte nuclear factors (HNF) 4-alpha, 1-alpha, and 1-beta play a role in the regulation of glucose homeostasis and affect transcription of many genes in beta-cells. Defects in HNF lead to abnormal glucose level. The exact mechanism of hyperglycemia is not clear, but it has been connected with reduced insulin secretory response to glucose, suggesting primary genetic defect in insulin secretion $[1,3,4]$.

Single genes at any stage of these pathways lead to monogenic diabetes (MGD) also known as MODY (maturity-onset diabetes of the young). MGD is a heterogeneous group of rare forms of diabetes. The mutation might occur de novo or might be inherited dominantly or recessively $[4,5,6]$. 
MGD can be detected in infancy, as well as in adolescence or in adulthood. The one present in infancy is called neonatal diabetes mellitus (NDM). NDM is defined as diabetes, which occurs in the first 6 months of life [2] and has an estimated incidence of around 1 in 200,000 live births $[7,8]$. It is divided into two clinical subtypes: transient neonatal diabetes mellitus (TNDM), which can resolve after a few weeks or months and permanent neonatal diabetes mellitus (PNDM), which requires treatment following diagnosis [7]. According to different studies $50 \%$ of cases of PNDM and $20 \%$ of TNDM are caused by mutations of the KATP channel genes (KCNJ11 or $A B C C 8$ ) encoding the Kir6.2 and SUR1 subunits respectively $[6,9,10]$. Patients diagnosed with KCNJ11 or ABCC8 mutations are able to switch from insulin injection to orally administered sulphonylurea drugs. In addition, such a transfer allows lowering the level of glycated hemoglobin (HbA1c) and reduces microvascular complications [11]. On the other hand, insulin therapy is required for patients with other non-KATP channels forms of NDM.

Typically, the diagnosis of MGD in young adolescents is based on clinical characteristics including: family history of diabetes with an autosomal dominant mode of inheritance and non-ketotic diabetes with the age of onset before 25 years of age [12]. There are at least eight well known genes involved in these MGD (Table 1). Approximately $70 \%$ cases are caused by mutation in GCK, HNF1a or HNF4a [13, 14]. It is important to conduct the genetic diagnostics because MGD is commonly misdiagnosed. $90 \%$ of genetically confirmed monogenic diabetes is initially treated as type 1 diabetes mellitus (T1DM) or type 2 diabetes mellitus (T2DM) [15, 16, 17]. Appropriate diagnosis has profound impact not only on predicting clinical course of the disease and explaining other associated clinical features, but mostly on introducing proper treatment. Moreover, the exact diagnosis will also carry implications for the patient's relatives [18].

Finally, it is worth mentioning that there are a few genetic disorders associated with diabetes mellitus, including: Wolfram syndrome, also known as DIDMOAD (Diabetes Insipidus, Diabetes Mellitus, Optic Atrophy, and Deafness) or Alström syndrome.
Wolfram syndrome is caused by the mutation in at least two different genes: WFS1 and ZCD2. The reason of diabetes mellitus in Wolfram syndrome is impaired homeostasis of beta cells (increased apoptosis and/or failure of regenerative processes), however some clinical symptoms as ketosis prone juvenile diabetes and absence of obesity are similar to T1DM [19].

Alström syndrome is a rare genetic condition caused by mutations in the ALMS1 gene. It is characterized by multiorgan dysfunction, including endocrinologic features such as hyperinsulinemia and early-onset type 2 diabetes [20].

\section{Is monogenic diabetes undiagnosed and untreated?}

Recent data from American Diabetes Association (ADA) annual meeting sheds light on monogenic diabetes, especially on the lack of appropriate diagnosis and its consequences. It was emphasized that almost no training has taken place in this area. Commonly, for clinicians, there exist only two types of diabetes: type 1 and type 2 . In everyday practice other types of diabetes are forgotten [21]. It results mostly from the fact that the exact prevalence of MGD is unknown, but based on different studies it may comprise $1-4 \%$ of all cases of diabetes [13, 14, 22-26]. Moreover, early symptoms might be mistaken and MGD is frequently diagnosed as T1DM [15, 16, 17]. Patients with no evidence of pancreatic autoantibodies are classified as having antibody-negative T1DM or idiopathic diabetes [27]. Lack of autoimmune markers might be useful as an indicator for further genetic testing, especially if measured at diagnosis. Most patients with T1DM will have detectable islet cell autoantibodies and less than $10 \%$ will need a combined antibody testing, including glutamic acid decarboxylase autoantibodies (GADab), protein tyrosine phosphatase-like protein autoantibodies (IA2ab), insulin antibodies (IAA) [28, 29]. The autoimmunity detection rate will rise up to $98 \%$, if the measurement of zinc transporter-8 autoantibodies (ZnT8A) will be added [30]. Assessment of autoantibodies level at the diabetes onset plays the key role in differential diagnosis, because islet cell autoantibodies may disap-

Table 1. Genes in which mutations cause MGD characteristic for neonates, young children and adolescents or adults

\begin{tabular}{lcccccccc}
\hline Affected gene & HFN4A & GCK & HFN1A & IPF 1 & HFN1B & NeuroD1 & KCNJ11 & ABCC8 \\
\hline Symbol & MODY 1 & MODY 2 & MODY 3 & MODY 4 & MODY 5 & MODY 6 & PNDM & TNDM \\
\hline Chromosome locus & 20q13 & $7 p 13$ & $12 q 24$ & $13 q 12$ & $17 q 12$ & $2 q 31$ & & \\
\hline Function & $\begin{array}{c}\text { Transcription } \\
\text { factor }\end{array}$ & $\begin{array}{c}\text { Glycolytic } \\
\text { enzyme }\end{array}$ & $\begin{array}{c}\text { Transcription } \\
\text { factor }\end{array}$ & $\begin{array}{c}\text { Transcription } \\
\text { factor }\end{array}$ & $\begin{array}{c}\text { Transcription } \\
\text { factor }\end{array}$ & $\begin{array}{c}\text { Transcription } \\
\text { factor }\end{array}$ & $\begin{array}{c}\text { coding } \\
\text { Kir6.2 }\end{array}$ & $\begin{array}{c}\text { coding } \\
\text { sUR1 }\end{array}$ \\
\hline
\end{tabular}


pear over time after disease onset in previously proven autoimmune diabetes [31]. The prevalence of GADab or/and IA-2ab is less than $1 \%$ in patients diagnosed with GCK, HNF1a /HNF4a and HNF1B mutations. Therefore, positive results of islet autoantibodies make monogenic diabetes very unlikely [32].

Very interesting research was conducted by the Search for Diabetes in Youth Study Group (SEARCH) in the United States. This group screened for three most common MGD subtypes among SEARCH participants who were diabetic autoantibodies (DDA) negative with fasting C-peptide $\geqslant 0.8 \mathrm{ng} / \mathrm{ml}$. The frequency of having one of three commonest mutations was $8 \%$ and the frequency of mutation carriers was $4.4 \%$ for HNF1a, $1.2 \%$ for HFN $4 \alpha$ and $2.4 \%$ for GCK. Only $6 \%$ of MGD positive individuals received proper diagnosis and adequate treatment. Most MGD(+) participants were misdiagnosed and classified as T1DM (36\%) or T2DM (51\%). According to this study the estimated prevalence of these three MGD subtypes is at least $1.2 \%$ in the US population of pediatric diabetes [33]. Similar trends can also be noticed in European countries. The first prevalence study of MGD in a nationwide population of children with diabetes was conducted in Norway and showed that the minimum prevalence of MGD in 2,756 children with newly diagnosed diabetes was 1.1\% [32]. German/Austrian study of 40,757 children and adolescents revealed the prevalence of clinical and genetic MGD $0.83 \%$ and $0.65 \%$, respectively [14]. A nationwide genetic screening campaign among Polish diabetic children found the prevalence of MGD between 4.1\% in 2005 and $3.2 \%$ in 2011. GCK mutations were the most often detected form of MGD and they account for $83 \%$. The frequency of other types was $7 \%$ for neonatal diabetes, $4 \%$ for HNF1 $\alpha / H N F 4 \alpha$ mutations, $2 \%$ for HNF1B mutations and diabetes in Wolfram and Alström syndromes $2 \%$ and $1 \%$, respectively. This study showed that MGD is more common in pediatric population with low frequency of obesity rather than T2DM or cystic fibrosis-related diabetes (CFRD) [26].
When to suspect that the diagnosis of diabetes type may not be accurate?

Available epidemiological data indicates that despite MGD is a rare genetic condition, it should be considered in unusual diabetic cases. Uncommon course of diabetes may suggest to the physician that this is different than T1DM or T2DM and some genetic test should be considered. There are a few clinical features which may be useful in making diagnosis. Based on International Society for Pediatric and Adolescent Diabetes (ISPAD) Clinical Practice Consensus Guidelines MGD should be pondered if diabetes was diagnosed within the first 6 month of life, family history indicates diabetes with a parent affected or mild fasting hyperglycemia (5.5-8.5 mmol/l) accompanied by other extra pancreatic features occurs. Furthermore, in case of previously recognized T1DM, with prolonged "honeymoon" phase after 3 years of diabetes onset, with still maintained significant endogenous insulin production, should raise doubts about proper diagnosis. Mainly, doctor should be suspicious, if there was not any evidence of autoimmunity process at the beginning of the diabetes. On the other hand, lack of acanthosis nigricans and other features of insulin resistance, including fasting $C$ peptide within the normal range, low C-reactive protein level and ethnic backgrounds with a low prevalence of T2DM may suggest a possibility of monogenic diabetes in patients previously diagnosed as T2DM [35]. The similarities and differences between MGD, T1DM and T2DM are shown in Table 2 [36].

Furthermore, the clinical features should be considered together rather than separately. Moreover, the patient with a diagnosis of MGD should present the features of a specific genetic subtype of MGD (Table 3) [35].

\section{Why to diagnose monogenic diabetes?}

An accurate diagnosis of MGD is not meaningless. First of all, it allows understanding the patient's origin of diabetes and explaining other associated clinical fea-

Table 2. The similarities and differences between MGD, T1DM and T2DM, in modification

\begin{tabular}{lccc}
\hline Features & T1DM & T2DM & MGD \\
\hline Non-insulin dependent & NO & YES/NO & YES \\
\hline Parents affected & $0-1$ & $0-2$ & 1 \\
\hline Age of onset $<25 \mathrm{yr}$ & YES & YES & YES \\
\hline Obesity & Uncommon & Common & Uncommon \\
\hline Acanthosis nigricans & Uncommon & Common & Uncommon \\
\hline Racial groups (Type 2 prevelance) & Low & High & Low \\
\hline C-Reactive Protein & Normal & High & Low \\
\hline Presence of B-cell antibodies & $>90 \%$ & Rare & Rare \\
\hline
\end{tabular}


Table 3. The most characteristics of common forms of monogenic diabetes

\begin{tabular}{ccccc}
\hline & Inheritance & $\begin{array}{c}\text { Typical age of presentation in } \\
\text { pediatric clinic (range) }\end{array}$ & $\begin{array}{c}\text { Typical glucose presentation } \\
\text { (range) } \mathrm{mmol} / \mathrm{l}\end{array}$ & Other clinical features \\
\hline HNF1A & Dominant & $14(4-18)$ & $17(11-26)$ & Large increase of glucose level in an OGTT \\
\hline & & & Low renal threshold \\
\hline & & & Progresive hyperglycemia with age \\
\hline HNF4A & Dominant & $17(5-18)$ & $15(9-20)$ & Sensitive to sulphonylureas \\
\hline & & & $11(5.5-16)$ & Similar to HNF1A, but renal threshold normal \\
\hline GCK & Dominant & $10(0-18)$ & & Very common macrosomia \\
\hline & & & Usually incidential finding at diagnosis \\
\hline
\end{tabular}

tures. Secondly, it gives the physician an opportunity to predict the clinical course of the disease. Finally, it is paramount to introduce appropriate treatment. Such patients might not need any treatment or might be able to switch from insulin injections to tablets such as sulfonylurea $[11,37]$. As a final point, it is worth mentioning that an exact diagnosis also has implications for other family members often modifying their diagnosis and treatment as well as allowing proper genetic counselling.

Typically, individuals with glucokinase mutation present the fasting hyperglycemia, however their blood glucose level is regulated at a higher set point [38]. Commonly, such patients are diagnosed incidentally on routine physical examination or during pregnancy in case of women. Usually, deterioration in glycaemia control is not observed and they do not develop any diabetic chronic complications even when they have not received any treatment throughout life [39]. Therefore there is a clear conclusion: these patients do not need treatment, especially in pediatric age. Confirmed genetic diagnosis allows avoiding repeated, unnecessary diagnostic tests and explains disturbances of glucose metabolism in case of additional diseases or pregnancy, which can exacerbate clinical manifestation of diabetes mellitus.

On the other hand, diabetes caused by mutations of the HNF-1 $1 \alpha$ gene and the HNF- $4 \alpha$ gene requires pharmacological treatment. Patients with HNF-1a gene mutation, typically are young, slim adults with symptomatic diabetes, glucose range between 300-500 $\mathrm{mg} / \mathrm{dl}$ and can present extrapancreatic features such as renal cysts and liver adenomatosis. They demonstrate progressive deterioration in glycemic control throughout life and they are at risk of developing diabetes-related chronic complications [38, 40]. An important point is that these patients are extremely sensitive to low dose sulphonylureas [41, 42]. Moreover, patients receiving sulphonylureas achieved better glycemic control than those on insulin treatment [43].

Diabetes caused by mutations of the HNF- $4 \alpha$ is less common than the mutation of the HNF-1 $\alpha$ and should be considered when the mutation of HNF-1a gene is not detected and the clinical features strongly suggest the mutation of HNF-1 $\alpha$ gene [44]. These patients are also sensitive to sulphonylureas [45].

\section{Conclusions}

Despite the fact that the MGD is a relatively rare genetic condition and there is lack of studies which would allow estimating the true prevalence of these diseases it should be always considered in the case of unusual course of diabetes. According to the latest ADA meeting's opinions, in some cases the possibility that a patient has other types of diabetes than type 1 or type 2 should be taken into consideration. MGD is a challenge for physicians due to its rare occurrence. As a consequence patients are misdiagnosed and receive incorrect treatment. Patients for genetic testing should be selected carefully. Prior to making a decision to perform genetic tests the clinician should analyze the family history for diabetes. It is crucial to determine the exact age of diabetes onset, especially if diagnosis was made earlier than 6 months after birth. In addition, assessment of autoantibodies level at the time of diabetes diagnosis is one of the most important aspects influencing appropriate diagnosis. Preferably combined antibody testing should be performed. The website www.diabetesgenes.org provides information for patients and professionals on research and clinical care in genetic types of diabetes (Probability Calculator for patients diagnosed $<35$ years based on clinical criteria). Determining the cause of monogenic diabetes may 
have implications for treatment, prognosis and genetic counselling; not only for a patient, but for other family members as well.

\section{Key points}

- The most frequent forms of monogenic diabetes are GCK, HNF1 $\alpha$ andHNF4 $\alpha$ MODY.

- Patients with absence of islet autoantibodies, especially when measured at diabetes diagnosis should be evaluated for either GCK or transcription factors MGD.

- In MGD characteristic for young adolescents the genetic subtype determines clinical picture and treatment response.

- Identification of a patient with MGD may allow switching from insulin injection to tablets such as sulphonylurea.

- Individuals with GCK mutations rarely need pharmacological treatment and the majority can be managed with diet alone.

\section{References}

1. Matschinsky F, Liang Y, Kesavan P, et al. Glucokinase as pancreatic beta cell glucose sensor and diabetes gene. J Clin Invest. 1993;92:2092.

2. Gloyn AL, Pearson ER, Antcliff JF, Proks P, Bruining GJ, Slingerland AS, et al. Activating mutations in the gene encoding the ATP-sensitive potassium-channel subunit Kir6.2 and permanent neonatal diabetes. N Engl J Med. 2004;350(18):1838-49.

3. Hansen T, Eiberg H, Rouard M, et al. Novel MODY3 mutations in the hepatocyte nuclear factor-1alpha gene: evidence for a hyperexcitability of pancreatic beta-cells to intravenous secretagogues in a glucose-tolerant carrier of a P447L mutation. Diabetes. 1997;46:726.

4. Vaxillaire M, Bonnefond A, Froguel P. The lessons of early -onset monogenic diabetes for the understanding of diabetes pathogenesis. Best Pract Res Clin Endocrinol Metab. 2012;26(2):171-87, DOI: 10.1016/j.beem.2011.12.001.

5. Hattersley AT. Molecular genetics goes to the diabetes clinic. Clin Med. 2005;5(5):476-81.

6. Molven A, Njølstad PR. Role of molecular genetics in transforming diagnosis of diabetes mellitus. Expert Rev Mol Diagn. 2011;11(3):313-20, DOI: 10.1586/erm.10.123.

7. Temple IK, Gardner RJ, Mackay DJ, Barber JC, Robinson DO, Shield JP. Transient neonatal diabetes: widening the understanding of the etiopathogenesis of diabetes. Diabetes. 2000;49(8):1359-66.

8. Slingerland, AS, Shields BM, Flanagan SE, Bruining GJ, Noordam K, Gach A, et al. Referral rates for diagnostic testing support an incidence of permanent neonatal diabetes in three European countries of at least 1 in 260,000 live births. Diabetologia. 2009;52:1683-5.

9. Babenko AP, Polak M, Cave H, Busiah K, Czernichow P, Scharfmann R. Activating mutations in the ABCC8 gene in neonatal diabetes mellitus. N Engl J Med. 2006;355: 456-66.

10. Flanagan SE, Patch AM, Mackay DJ, Edghill EL, Gloyn AL, Robinson D, et al. Mutations in ATP-sensitive K+ channel genes cause transient neonatal diabetes and permanent diabetes in childhood or adulthood. Diabetes. 2007;56: 1930-7.

11. Pearson ER, Flechtner I, Njølstad PR, Malecki MT, Flanagan SE, Larkin B, et al. Neonatal Diabetes International Collaborative Group. Switching from insulin to oral sulfonylureas in patients with diabetes due to Kir6.2 mutations. N Engl J Med. 2006;355(5):467-77.

12. Fajans S, Bell G, Polonsky K. Molecular Mechanisms and Clinical Pathophysiology of Maturity-Onset Diabetes of the Young. N Engl J Med. 2001;345:971-980, DOI: 10.1056/NEJMra002168.

13. Shields BM, Hicks S, Shepherd MH, Colclough K, Hattersley AT, Ellard S. Maturity-onset diabetes of the young (MODY): how many cases are we missing? Diabetologia. 2010;53(12):2504-8, DOI: 10.1007/s00125-010-1799-4.

14. Schober E, Rami B, Grabert M, Thon A, Kapellen T, Reinehr T. Phenotypical aspects of maturity-onset diabetes of the young (MODY diabetes) in comparison with Type 2 diabetes mellitus (T2DM) in children and adolescents: experience from a large multicentre database. Diabet Med. 2009;26(5):466-73, DOI: 10.1111/j.14645491.2009.02720.x.

15. Møller AM, Dalgaard LT, Pociot F, Nerup J, Hansen T, Pedersen 0 . Mutations in the hepatocyte nuclear factor-1alpha gene in Caucasian families originally classified as having Type I diabetes. Diabetologia. 1998;41(12):1528-31.

16. Slingerland AS, Hattersley AT. Mutations in the Kir6.2 subunit of the KATP channel and permanent neonatal diabetes: new insights and new treatment. Ann Med. 2005;37(3):186-95.

17. Ellard S, Allen LI, Gallen IW, Gillespie KM, Bingley PJ, Hattersley AT. Identifying hepatic nuclear factor 1alpha mutations in children and young adults with a clinical diagnosis of type 1 diabetes. Lambert AP. Diabetes Care. 2003;26(2):333-7.

18. Murphy R, Ellard S, Hattersley AT. Clinical implications of a molecular genetic classification of monogenic bold beta-cell diabetes. Nat Clin Pract Endocrinol Metab. 2008;4:200-13, DOI: 10.1038/ ncpendmet0778.

19. Cano A, Molines L, Valéro R, Simonin G, Paquis-Flucklinger V, Vialettes B. Microvascular Diabetes Complications in Wolfram Syndrome (Diabetes Insipidus, Diabetes Mellitus, Optic Atrophy, and Deafness [DIDMOAD]): An ageand duration-matched comparison with common type 1 diabetes. Diabetes Care. 2007;30:2327-30; published ahead of print May 29, 2007, DOI: 10.2337/dc07-0380.

20. Marshall JD, Maffei P, Collin GB, Naggert JK. Alström syndrome: genetics and clinical overview. 20. Curr Genomics. 2011;12(3):225-35, DOI: 10.2174/138920211795677912.

21. http://www.medscape.com/viewarticle/807533.

22. Shankar RK, Pihoker C, Dolan LM, et al. Permanent neonatal diabetes mellitus: prevalence and genetic diagnosis in the SEARCH for Diabetes in Youth Study. Pediatr Diabetes. 2013;14(3):174-80, DOI: 10.1111/pedi.12003. Epub 2012 Oct 10.

23. Wiedemann B, Schober E, Waldhoer T, et al. Incidence of neonatal diabetes in Austria-calculation based on the 
Austrian Diabetes Register. Pediatr Diabetes. 2010;11: $18-23$.

24. Eide $S A$, Raeder $H$, Johansson $S$, et al. Prevalence of HNF1A (MODY3) mutations in a Norwegian population (the HUNT2 Study). Diabet Med J Br Diabet Assoc. 2008;25:775-81.

25. Kropff J, Selwood MP, McCarthy MI, Farmer AJ, Owen KR. Prevalence of monogenic diabetes in young adults: acommunity-based, cross-sectional study in Oxfordshire, UK. Diabetologia. 2011;54:1261-3.

26. Fendler W, Borowiec M, Baranowska-Jazwiecka A, et al. Prevalence of monogenic diabetes amongst Polish children after a nationwide genetic screening campaign. Diabetologia. 2012;55:2631-5.

27. American Diabetes Assosiation. Diagnosis and Classification of Diabetes Mellitus. Diabetes Care January. 2012; 35 (Suppl. 1):64-71.

28. Bingley PJ, Bonifacio E, Williams AJ, Genovese S, Bottazzo GF, Gale EA. Prediction of IDDM in the general population: strategies based on combinations of autoantibody markers. Diabetes. 1997;46(11):1701-10.

29. Sabbah E, Savola K, Ebeling T, Kulmala P, Vähäsalo P, Ilonen J, et al. Genetic, autoimmune, and clinical characteristics of childhood- and adult-onset type 1 diabetes. Diabetes Care. 2000;23(9):1326-32.

30. Wenzlau JM, Juhl K, Yu L, Moua O, Sarkar SA, Gottlieb P, et al. The cation efflux transporter ZnT8 (SIc30A8) is a major autoantigen in human type 1 diabetes. Proc Natl Acad Sci USA. 2007;104(43):17040-5. Epub 2007 Oct 17.

31. Borg H, Marcus C, Sjöblad S, Fernlund P, Sundkvist G. Islet cell antibody frequency differs from that of glutamic acid decarboxylase antibodies/IA2 antibodies after diagnosis of diabetes. Acta Paediatr. 2000;89(1):46-51.

32. McDonald TJ, Colclough K, Brown R, Shields B, Shepherd $M$, Bingley $P$, et al. Islet autoantibodies can discriminate maturity-onset diabetes of the young (MODY) from Type 1 diabetes. Diabet Med. 2011;28(9):1028-33, DOI: 10.1111/j.1464-5491.2011.03287.x.

33. Gilliam LK, Pihoker C, Ellard S, Hattersley AT, Dabelea D, Davis C, et al. for the SEARCH for Diabetes in Youth Study Group. Prevalence, Characteristics and Clinical Diagnosis of Maturity Onset Diabetes of the Young Due to Mutations in HNF1A, HNF4A, and Glucokinase: Results from the SEARCH for Diabetes in Youth. J Clin Endocrinol Metab. 2013 Jun 14.

34. Irgens HU, Molnes J, Johansson BB, Ringdal M, Skrivarhaug $T$, Undlien $D E$, et al. Prevalence of monogenic diabetes in the population-based Norwegian Childhood Diabetes Registry. Diabetologia. 2013;56(7):1512-9, DOI: 10.1007/s00125-013-2916-y. Epub 2013 Apr 27.

35. http://www.ispad.org/content/ispad-clinical-practiceconsensus-guidelines-2009.
36. Thanabalasingham G, Owen KR. Clinical Review: Diagnosis and management of maturity onset diabetes of the young (MODY). BMJ. 2011;343, DOI: http://dx.doi.org/ 10.1136/bmj.d6044.

37. Hattersley AT, Pearson ER. Minireview: pharmacogenetics and beyond: the interaction of therapeutic response, beta-cell physiology, and genetics in diabetes. Endocrinology. 2006;147(6):2657-63. Epub 2006 Mar 23.

38. Stride A, Vaxillaire M, Tuomi T, Barbetti F, Njølstad PR, Hansen $T$, et al. The genetic abnormality in the beta cell determines the response to an oral glucose load. Diabetologia. 2002;45(3):427-35.

39. Velho G, Blanché $H$, Vaxillaire $M$, Bellanné-Chantelot $C$, Pardini VC, Timsit J, et al. Identification of 14 new glucokinase mutations and description of the clinical profile of 42 MODY-2 families. Diabetologia. 1997;40(2):217-24.

40. Pearson ER, Liddell WG, Shepherd M, et al. Sensitivity to sulphonylureas in patients with hepatocyte nuclear factor 1 alpha gene mutations: evidence for pharmacogenetics in diabetes. Diab Med. 2000;17:543-5.

41. Pearson ER, Starkey BJ, Powell RJ, et al. Genetic aetiology of hyperglycaemia determines response to treatment in diabetes. Lancet. 2003;362(9392):1275-81.

42. Delépine M, Nicolino M, Barrett T, Golamaully M, Lathrop GM, Julier C. EIF2AK3, encoding translation initiation factor 2-alpha kinase 3, is mutated in patients with Wolcott-Rallison syndrome. Nat Genet. 2000;25(4):406-9.

43. Byrne MM, Sturis J, Menzel S, Yamagata K, Fajans SS, Dronsfield MJ, et al. Altered insulin secretory responses to glucose in diabetic and nondiabetic subjects with mutations in the diabetes susceptibility gene MODY 3 on chromosome 12. Diabetes. 1996;45(11):1503-10.

44. Pearson ER, Pruhova S, Tack CJ, Johansen A, Castleden $\mathrm{HA}$, Lumb PJ, et al. Molecular genetics and phenotypic characteristics of MODY caused by hepatocyte nuclear factor 4alpha mutations in a large European collection. Diabetologia. 2005;48(5):878-85. Epub 2005 Apr 14.

45. Fajans SS, Brown MB. Administration of sulfonylureas can increase glucose-induced insulin secretion for decades in patients with maturity-onset diabetes of the young. Diabetes Care. 1993;16(9):1254-61.

\section{Correspondence address:} Bogda Skowrońska Department of Pediatric Diabetes and Obesity Poznan University of Medical Sciences 27/33 Szpitalna Street, 60-572 Poznań, Poland phone: +48618491420

fax: +48618491492 email: bskowron@ump.edu.pl 